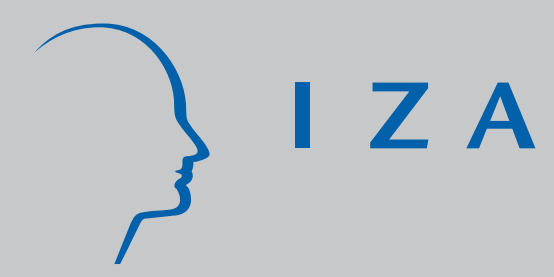

IZA DP No. 1840

Endogenous Assimilation and Immigrant Adjustment in Longitudinal Data

Michael Beenstock

Barry R. Chiswick

Ari Paltiel

November 2005 


\title{
Endogenous Assimilation and Immigrant Adjustment in Longitudinal Data
}

\author{
Michael Beenstock \\ Hebrew University of Jerusalem \\ Barry R. Chiswick \\ University of Illinois at Chicago \\ and IZA Bonn \\ Ari Paltiel \\ Central Bureau of Statistics, Israel
}

\author{
Discussion Paper No. 1840 \\ November 2005
}

\author{
IZA \\ P.O. Box 7240 \\ 53072 Bonn \\ Germany \\ Phone: +49-228-3894-0 \\ Fax: +49-228-3894-180 \\ Email: iza@iza.org
}

\begin{abstract}
Any opinions expressed here are those of the author(s) and not those of the institute. Research disseminated by IZA may include views on policy, but the institute itself takes no institutional policy positions.

The Institute for the Study of Labor (IZA) in Bonn is a local and virtual international research center and a place of communication between science, politics and business. IZA is an independent nonprofit company supported by Deutsche Post World Net. The center is associated with the University of Bonn and offers a stimulating research environment through its research networks, research support, and visitors and doctoral programs. IZA engages in (i) original and internationally competitive research in all fields of labor economics, (ii) development of policy concepts, and (iii) dissemination of research results and concepts to the interested public.
\end{abstract}

IZA Discussion Papers often represent preliminary work and are circulated to encourage discussion. Citation of such a paper should account for its provisional character. A revised version may be available directly from the author. 
IZA Discussion Paper No. 1840

November 2005

\section{ABSTRACT}

\section{Endogenous Assimilation and Immigrant Adjustment in Longitudinal Data}

We create a longitudinal data set by matching immigrants in Israel's censuses for 1983 and 1995. These panel data reject the Immigrant Assimilation Hypothesis (IAH), which predicts that immigrants with shorter durations in 1983 should have experienced faster earnings growth between 1983 and 1995. By contrast, IAH is corroborated by the synthetic cohort methodology (SCM) over the same period. We suggest that SCM is subject to survivor bias, which increases the apparent degree of assimilation. We show that since the return to destination-specific skills increased during this period because of the very large immigration, the assimilation curve changed its shape in a way that made it difficult to estimate even using panel data.

JEL Classification: J24, J31, J61, F22

Keywords: immigrants, assimilation, panel data

Corresponding author:

Barry R. Chiswick

Department of Economics (M/C 144)

University of Illinois at Chicago

601 South Morgan Street (2103 UH)

Chicago, IL 60607-7121

USA

Email: brchis@uic.edu 


\section{Introduction}

From the start of research on the economic adjustment of immigrants in the destination country an important role has been played by duration in the destination, often expressed as "Years since Migration" (Chiswick 1978b). The earliest studies ${ }^{1}$, and most studies to this day, use cross-sectional data to analyze the effect of duration. However, even in the earliest research there has been an awareness of the potential biases in using cross-sectional data to infer dynamic behavior (Chiswick 1980). The ideal solution seemed to be to use longitudinal (panel) data, by following the same immigrants over time rather than comparing different immigrants who arrived in various time periods (cross-sectional data). However, longitudinal data on the wages of immigrants tend to be scarce $^{2}$.

To overcome this obstacle Borjas (1985) proposed applying the "synthetic cohort methodology" (SCM), using a succession of cross-sections to construct synthetic panel data. For example, immigrants who immigrated aged 20 in 1970 may be compared with immigrants aged 30 in 1980 that immigrated in 1970, and with immigrants aged 40 in 1990 who immigrated in 1970. SCM does not compare the same immigrants in 1970, 1980 and 1990, because of re-migration, deaths and sampling issues, but at least it goes some way to controlling for cohort effects.

In this paper we use a large panel sample of immigrants in Israel observed at two points in time, in 1983 and 1995. Since the data come from matched census data the problem of comparing different samples over the intervening 12 years does not apply. Nevertheless, there are other types of attrition in the data (such as emigration and mortality) for which, fortunately, we are in the unusual position of being able to control. The immigrant assimilation hypothesis (IAH) predicts that, given everything else, the growth of earnings between 1983 and 1995 should be greater for immigrants who had been less time in Israel in 1983. Since the source of these data is from the matched censuses of 1983 and 1995, we may compare empirical tests of IAH using three methodologies, the original cross-section methodology due to Chiswick (1978b), SCM due to Borjas (1985), and panel data analysis. We find that IAH is confirmed by the first two methodologies but it is not supported by the longitudinal data.

Since SCM allows for cohort effects the differences between results obtained by SCM and cross-section data are mainly due to differences in cohort qualities. Cohort

\footnotetext{
${ }^{1}$ See Hanoch (1961) and Kuznets (1973).

${ }^{2}$ For a useful survey of such data see Black et al (2003).
} 
quality may change due to a wide variety of economic and policy factors both within the destination country and in the countries of origin. In the absence of cohort effects SCM and cross-section data should give similar results. However, as Borjas himself (1985) was aware, the main difference between SCM and panel data analysis is that SCM may contain survivor bias. Suppose that fitter workers survive longer in the labor market due to selective emigration, labor force withdrawal or mortality. In this case the average fitness of the 1970 synthetic immigrant cohort will grow over time and will be larger in 1990 than in 1980. Therefore the earnings of immigrants, who arrived in 1970, might have increased between 1980 and 1990, not because of assimilation but simply because of survivor bias. Since panel data compares the same immigrants in 1980 and 1990 this type of survivor bias does not arise.

Since cohort and survivor bias do not apply to panel data, tests of IAH using panel data will be more reliable. We suggest that the corroboration of IAH using SCM and its rejection using panel data most probably stems from survivor bias in SCM. Using panel data for Canada during the 1990s, Hum and Simpson (2000, 2004a) were unable to corroborate IAH during the first 5 years. Yet during this same period SCM corroborates IAH in Canada (Frenette and Morissette 2003, Hum and Simpson 2004b). Hu (2000) comes to a similar conclusion regarding US immigrants; evidence in favor of IAH according to SCM either weakens or disappears altogether in panel data. It is too early to conclude that evidence in favor of IAH using SCM is a statistical illusion due to survivor bias. Indeed, Duleep and Dowhan (2002) report that IAH is supported by matched panel data in the U.S.

Unfortunately, panel data do not solve all the problems. Panel data overcome the problem of cohort heterogeneity, but they do not overcome the problem of structural change in immigrant absorption. For example, IAH does not imply that the return to duration is constant over time. This return will depend upon market forces that influence the price of destination-specific human capital. If this return happens to increase, immigrants will have a greater incentive to invest in local skills ${ }^{3}$. We show that this model of "endogenous assimilation" implies that the assimilation curve may change over time, due to a change in the returns to destination specific human capital or the rate of investment thereby inducing "period effects" (Chiswick 1986). In an ideal experiment we would want to increase duration for the same immigrants holding time, age, etc. constant

\footnotetext{
${ }^{3}$ The problem is analogous to investment in education when the return to education is endogenous.
} 
to identify the effect of duration on assimilation unambiguously. But this is obviously impossible. It would not matter if there were no period effects. In this case an extra year's duration means that the immigrant is a year older. If the age effect is identified using data for natives, under the assumption that the age effects are the same for immigrants and natives the assimilation effect is identified too. However, if there are period effects even panel data cannot identify the assimilation effect.

The presence of period effects means that IAH (or indeed any other theory in which the structural model varies over time) is untestable in principal. In practice, however, there must be good reason for suspecting period effects. We have reason to suspect such effects in Israel between 1983 and 1995 because mass immigration from the former USSR in the 1990s, which raised the population by about 15 percent, might have altered the return to investing in destination (Israel) specific skills. We show that in this eventuality IAH might predict that the rate of growth of immigrant earnings between 1983 and 1995 does not depend on duration in 1983.

In section 2 we review the relevant literature. Section 3 sets out our theory of endogenous assimilation, which underpins the period effects model. Econometric methodology is discussed in Section 4. The data are presented in Section 5. Section 6 compares empirical tests of IAH using cross-section data in 1983 and 1995, using SCM based on 1983 and 1995, and using panel data observed in 1983 and 1995. Section 7 is a summary and conclusion.

\section{Cross-Sectional vs. Longitudinal Data}

The earning-duration profile estimated from cross-sectional data can be either an upward or downward biased estimate of the true longitudinal effect. Consider just two issues, selective exit (due to withdrawal from the labor force, return migration or migration to a third country or the death of immigrants), and changes in the unmeasured dimensions of skill ("quality") of new immigrant cohorts. If, other things being the same, the least successful of the immigrants are more likely to withdraw from wage earning, leave the destination or to die than the more successful, or if there is a decline over time in the unmeasured dimensions of immigrant quality, then cross-sectional data will exaggerate (bias upward) the rise in earnings with duration. ${ }^{4}$ On the other hand, if the

\footnotetext{
${ }^{4}$ There is a general tendency for economic migrants, whether international or internal migrants, to be favorably self-selected. Return migrants, on the other hand, are likely to be less favorably selected than the
} 
successful leave wage and salary employment by becoming self-employed, the crosssection data underestimates (biases downward) the rise in wage and salary earnings with duration in the destination. The same applies if the successful re-migrate, are more likely to die, or if unmeasured quality of successive cohorts of immigrants increases over time.

SCM does not solve the problem of selective exit from the data. SCM is also sensitive to measurement error in the characteristics that define the cohort. When based on a sample, SCM involves different people in the same "cohort," although this problem is mitigated by large random samples. SCM is also subject to survivor bias mentioned in Section 1. Finally, SCM is subject to the difficulty of disentangling longitudinal changes from period effects (Chiswick 1986, Duleep and Regets 1996).

\subsection{Empirical Analysis using Panel Data}

A preferred solution has been to use longitudinal data that track the progress of the same individuals over time. Unfortunately, longitudinal data on immigrants, or on the general population that includes a sufficient number of immigrants for a meaningful analysis, are quite scarce. The immigrant longitudinal surveys tend to have relatively small samples and short durations. Some studies that have used longitudinal data on adult males in the labor market include: (1) occupation in 1965 and 1970 in the U.S. 1970 Census (Chiswick, 1978a), (2) earnings in the National Longitudinal Survey of Adult Males (Chiswick, 1980), (3) earnings from matched samples from the Current Population Survey (Duleep and Regets 1997), (4) earnings and occupational attainment from the Longitudinal Survey of Immigrants in Australia (Chiswick, Lee and Miller 2005, Chiswick and Miller 2005), (5) earnings of Canadian immigrants from the Survey of Labour and Income Dynamics (Hum and Simpson 2000, 2004a), and (6) earnings of scientists from the National Science Foundation database (Borjas 1989), although the latter also suffers from selective movement in and out of scientific occupations. ${ }^{5}$

In addition to data availability and sample size issues, longitudinal data raise other issues. One has to do with re-migrants, those who leave to return to their origin or to migrate to a third country. Is the research interest in immigrant adjustment solely limited to the "survivors", that is, those who remain in the destination for the entire period? Or, is the interest also in the adjustment of all of the "arrivals", including the survivors and

original economic migrants as they include those whose expectations regarding success in the destination were not fulfilled. See, for example, Beenstock (1996) and Hu (2000).

${ }^{5}$ Also, these immigrants had been in the US for an average of 19 years when the study began in 1974 . Most of the immigrants would surely have completed their assimilation by then. 
the "drop-outs". Attitudes regarding immigration law and absorption/assimilation policies might be sensitive to the extent to which there is exit of immigrants, the proportion who leave, when they leave and whether it is the most successful or the least successful who leave.

Another issue regarding longitudinal data is the separation of longitudinal changes from period or timing effects. In principle, this issue could be solved if there were a series of sufficiently long longitudinal surveys. Such data do not exist. Indeed, in immigrant adjustment, "time" enters in six ways: survey or census year, the respondent's year of birth, age of the respondent in the survey year, year of migration (immigration cohort), age at migration and duration in the destination. In a single cross section knowing any three of these six time dimensions for a respondent determines the values for the remaining three. Thus, for example, for a survey conducted in the year 2000, if year of migration and age are known, then so too are year of birth, age at migration and duration in the destination.

For various reasons, perhaps because of endogenous and exogenous factors, the measured and unmeasured characteristics and adjustment process of immigrants may vary across time. This cannot be discerned in a single cross-section. Longitudinal data can, in principle, trace an immigrant's adjustment process over time. A series of longitudinal surveys, perhaps each one starting with a new immigrant cohort, would provide an even richer array of data for separating effects due to timing (e.g., the business cycle), cohort (year of immigration) and assimilation (person specific) adjustments.

\subsection{Empirical Analyses in Israel}

Until the present study there have been virtually no longitudinal data on the earnings of immigrants in Israel. The Immigrant Absorption Surveys of the 1970s used by Beenstock (1996) and Beenstock, Chiswick and Repetto (2001) are longitudinal but did not include earnings. In any case they only cover the first few years after immigration. The Immigrant Employment Survey (IES), conducted by the Central Bureau of Statistics (CBS), followed-up two immigrant cohorts from the former USSR. The first cohort arrived towards the end of 1990, and panel data on some 3,000 immigrants were collected in the Spring of 1992, 1993, and 1994. The questionnaire for 1993 and 1994 included data on earnings. Data were collected in 1995 and 1996 for a second cohort that arrived in 1993. Because earnings data were collected in 1996 only the second round of IES cannot be used for investigating earnings dynamics. Data from the first round of IES were used 
by Shnor (1996) to investigate earnings dynamics between 1993 and 1994. For the 1,071 immigrants reporting earnings in both of these years, the rate of growth of real earnings was $18 \%$ overall, $15 \%$ for men and $23 \%$ for women. Since native wage growth was negative during this period, these data suggest a rapid rate of wage assimilation.

Beenstock and Fisher (1997) used Household Income Surveys to construct synthetic cohort data for the years 1990 - 1994. These data show that immigrant earnings assimilate with respect to native earnings, and that later cohorts tend to have a lower starting wage. These data were also used by Eckstein and Weiss (2004), who calculated normalized wage gaps between immigrants and natives. Their normalization procedure assumed that the returns to labor market experience and education within occupations among immigrants is the same as among natives. They also assumed that the occupations of immigrants and natives are exogenous. Controlling for three occupational groups they found evidence of earnings assimilation during the first half of the 1990s. However, when their results are extrapolated forward they imply that immigrant earnings do not fully converge upon native earnings. ${ }^{6}$ The same patterns emerged even when upward occupational mobility is taken into consideration.

Finally, Friedberg (2000) applied SCM using census data for Israel in 1972 and 1983. She found evidence of assimilation for all groups. Indeed, with the exception of immigrants from Asia and Africa (primarily from the Middle East and North Africa), she found that immigrant earnings eventually exceed the earnings of comparable natives. She also found that SCM produces similar results to cross-section results because there is no evidence of cohort effects in immigrant assimilation in Israel.

\section{Endogenous Assimilation}

\subsection{Microeconomics: Investment in Destination-specific Skills}

The earnings of immigrant $\mathrm{i}$ in the destination labor market at time $\mathrm{t}\left(\mathrm{W}_{\mathrm{it}}\right)$ are hypothesized to depend autonomously on time since migration $(\mathrm{t})$, the stock of destination skills (S) and the return to these skills $(\rho)$ :

$W_{i t}=f(t) \rho_{t} S_{i t}^{\alpha}$

There are diminishing returns to destination skills, hence $0<\alpha<1$. The autonomous time component is strictly increasing, hence $f^{n}>0$. Equation (1) implies that the rate of growth of earnings with respect to time since migration depends upon the rate of change

\footnotetext{
${ }^{6}$ This finding is consistent with the experience of refugees in other countries.
} 
in the return to local skills, the rate of autonomous assimilation and the rate of change of destination skills:

$\frac{\dot{W}_{i t}}{W_{i t}}=\frac{\dot{\rho}_{t}}{\rho_{t}}+\frac{f_{t}^{\prime}}{f_{t}}+\alpha \frac{\dot{S}_{i t}}{S_{i t}}$

In equation (2) the final term is a decision variable of the immigrant and is therefore endogenous.

The instantaneous change in skills depends upon investment effort in acquiring them (I), hence:

$\dot{S}_{i t}=I_{i t}$

Without loss of generality we assume that skills do not depreciate. The cost of investment is assumed to vary directly and increasingly with its intensity. It may be possible to acquire destination specific skills rapidly at great cost, but it is cheaper to spread the process over a longer period of time. For simplicity there is no saving, so consumption (C) is assumed to equal earnings minus the cost of investment in destination skills:

$$
\begin{aligned}
& C_{i t}=W_{i t}-C I_{i t}-I_{i t} g\left(I_{i t}\right) \\
& g{ }^{\prime}>0, g^{\prime}>0
\end{aligned}
$$

Where $\mathrm{c}$ denotes the fixed unit cost of investment $(\mathrm{c}>0)$ and $\mathrm{g}$ its variable cost. We assume $\mathrm{g}=\mathrm{I}^{\beta}$ with $\beta>1$, that is, the marginal cots of investment increases.

Immigrants choose an investment policy in destination skills so as to maximize the discounted value of consumption:

$$
U=\int_{0}^{T} C_{i t} e^{-\delta t} d t
$$

Dropping subscript $\mathrm{i}$ for convenience, the Hamiltonian for the immigrant's dynamic optimization problem is:

$$
H=C_{t} e^{-\delta t}+q_{t} I_{t}
$$

Where $\mathrm{q}$ is the shadow price of $\mathrm{S}$. The first order conditions are:

$$
\begin{aligned}
\frac{\partial H}{\partial I} & =-\left[c+(1+\beta) I_{t}^{\beta}\right] e^{-\delta t}+q_{t}=0 \\
-\dot{q}_{t} & =\alpha f(t) \rho S_{t}^{1-\alpha} e^{-\delta t}
\end{aligned}
$$

Equation (7) implies that optimal investment in local skills is equal to:

$$
I_{t}=\left[\frac{q_{t} e^{\delta t}-c}{1+\beta}\right]^{1 / \beta}
$$


That is, investment varies directly with q, the shadow value or return to destination skills, and inversely with the cost of investment (c and $\beta$ ). ${ }^{7}$ Equation (8) shows that $\mathrm{q}$ varies inversely with $\mathrm{S}$ as expected.

Substituting for $\mathrm{q}$, and dropping time subscripts for convenience, the first order conditions imply the following nonlinear differential equation in investment in destination skills:

$\delta c+\delta(1+\beta) I^{\beta}-\beta(1+\beta) I^{\beta-1} \dot{I}-\alpha f(t) \rho S^{\alpha-1}=0$

Equations (3) and (10) describe the dynamics of I and S. Substituting equation (3) into equation (10) for I gives rise to a second order nonlinear differential equation in S. This equation has two roots, which may provide theoretical justification to the shapes of the frequently observed assimilation curves reported by Chiswick (1978) and many others.

Since the system is nonlinear it does not have an analytical solution. Nevertheless, we may reveal its properties by solving it under the assumption that $\dot{I}=0$. In this case equation (10) implies the following solution for investment in destination skills:

$I=\left[\frac{\alpha f(t) \rho S^{\alpha-1}-\delta c}{\delta(1+\beta)}\right]^{1 / \beta}$

Equation (11) means that around the steady-state, investment in assimilation by the immigrant varies inversely with the stock of skills and directly with the return on these skills. Investment varies inversely with the fixed cost of acquiring these skills (c), their marginal cost $(\beta)$, and the discount rate $(\delta)$. Finally, investment varies directly with $f$, because autonomous and acquired skills happen to be gross complements in equation (1).

If and when investment in immigrant assimilation is completed $\mathrm{I}=0$, in which case the long run solution for S according to equation (10) is:

$S^{*}=\left[\frac{\delta c}{\alpha f(T) \rho}\right]^{1 / \alpha-1}$

Equation (12) states that the long run stock of destination skills varies directly with their return and inversely with the fixed cost of acquiring them (c). Note, however, that the variable cost $(\beta)$ does not enter equation (12) because this only affects the dynamics of adjustment. In equation (12) $\mathrm{f}(\mathrm{T})$ is the asymptote of autonomous absorption, which due to gross complementarity has a positive effect on the long run value of S. Finally, the long run value for $\mathrm{S}$ varies inversely with the discount rate.

\footnotetext{
${ }^{7}$ Equation (9) is entirely analogous to Tobin's q model, hence the use of q in equation (6).
} 
We may substitute the dynamic solution for $\mathrm{S}$ that is generated by equation (10) into equation (2) to determine the time path for the rate of growth of immigrant earnings. Since investment in $\mathrm{S}$ varies directly with $\rho$, the steepness of the assimilation curve varies directly with $\rho$, and inversely with c, $\beta$ and $\delta$. The effects of these parameters on the relationship between duration and earnings are illustrated in Figure 1. On arrival the immigrant earns $\mathrm{W}(0)=\rho_{0} \mathrm{f}(0) \mathrm{S}_{0}{ }^{\alpha}$. When he is fully assimilated at time $\mathrm{T}$ he earns $\mathrm{W}(\mathrm{T})$ $=\rho_{\mathrm{T}} \mathrm{f}(\mathrm{T}) \mathrm{S}^{* \alpha}$. Schedule $\mathrm{A}$ in Fig 1 illustrates the assimilation curve implied by equations (3) and (10). If $\beta$ happens to increase the new assimilation curve will look like schedule B, i.e. immigrants assimilate more slowly, but since $S^{*}$ does not depend upon $\beta$ the asymptote of B is the same as in A. If $\rho$ increases the assimilation curve will look like schedule $\mathrm{C}$. The asymptote is greater because $\mathrm{S}^{*}$ varies directly with $\rho$. Because it pays to acquire skills more rapidly the assimilation curve steepens. The same happens if c or $\delta$ decrease. Not surprisingly, Fig 1 shows that the assimilation curve depends upon the parameters of the model. We think that the key parameter of interest is $\rho$.

\subsection{Macroeconomics: The Return to Destination-specific Skills}

In this section a theoretical framework is proposed for determining $\rho{ }^{8} \mathrm{We}$ assume that immigrant labor is paid its marginal product, and the demand for immigrant labor (D), which varies directly with $\mathrm{S}$, also depends upon the capital stock (K), native employment (L), and a shift variable (Z), and inversely with immigrant wages (W):

$$
D=Z K L^{\phi} S^{\gamma} W^{-\eta}
$$

Constant returns to scale implies that the demand for immigrant labor is proportionate to the capital stock. Equation (13) implies that immigrant and native labor are not perfect substitutes. If immigrant and native labor are gross complements then $\phi>0$. The other parameters, $\gamma$ and $\eta$ are assumed to be positive.

In equilibrium the demand for immigrant labor is equal to supply $(\mathrm{N})$. The equilibrium immigrant wage is therefore equal to:

$$
W=\left(\frac{N}{Z K S^{\gamma} L^{\phi}}\right)^{-1 / \eta}=\left(\frac{N}{Z K L^{\phi}}\right)^{-1 / \eta} S^{\gamma / \eta}
$$

\footnotetext{
${ }^{8}$ Chiswick (1982) and Chiswick, Chiswick and Karras (1992) also analyze the effect of immigration on the rate of return to local or destination-specific human capital.
} 
Equation (14) states that immigrant earnings vary directly with Z, K, S and L (if $\phi>0$ ), and inversely with N. A comparison of equations (14) and (1) leads to the conclusions that $\alpha=\gamma / \eta$ and:

$$
\rho=\left(\frac{N}{Z K L^{\phi}}\right)^{-1 / \eta}
$$

Equation (15) specifies the determinants of $\rho$, the return to immigrant skills. The return varies directly with the capital stock $(K)$ since immigrant productivity varies directly with it. It also varies directly with $\mathrm{Z}$ because this too raises the productivity of immigrants. If, given everything else, immigrant employment increases, the return falls because immigrant earnings are lower. Finally, if native workers are gross complements to immigrants $(\phi>0)$, more native employment means a greater demand for immigrant workers, which increases their earnings and so the return to their skills. If, on the other hand, immigrant and native workers are gross substitutes $(\phi<0)$, the converse applies.

If these variables happen to change, the assimilation curve depicted in Figure 1 will change. For example, if a new wave of immigration raised the demand for existing immigrants, because they are endowed with both local and immigrant skills, this would increase Z, which would steepen the assimilation curve in Figure 1.

\section{Econometric Methodology}

In this section we discuss the implications of longitudinal data for the econometric estimation of the earnings assimilation curve for immigrants. We use the following notation:

$\mathrm{Y}_{\mathrm{it}}=\log$ of earnings for immigrant $\mathrm{i}=1,2, \ldots, \mathrm{N}$, in time period $\mathrm{t}$

$\mathrm{TSM}_{\mathrm{it}}=$ Time since migration of $\mathrm{i}$ in time $\mathrm{t}$

$\mathrm{X}_{\mathrm{i}}=$ demographic controls for $\mathrm{i}$

$\theta_{\mathrm{i}}=$ specific effect for $\mathrm{i}$

$\varepsilon_{\text {it }}=$ residual error with variance $\sigma_{\varepsilon}^{2}$

Note that X (e.g. gender, ethnicity) does not vary over time.

\subsection{Static Analysis}

We follow convention by assuming that the earnings assimilation curve is quadratic in TSM:

$\mathrm{Y}_{\mathrm{it}}=\alpha_{\mathrm{t}}+\beta_{\mathrm{t}} \mathrm{TSM}_{\mathrm{it}}-\gamma_{\mathrm{t}} \mathrm{TSM}_{\mathrm{it}}^{2}+\lambda_{\mathrm{t}} \mathrm{X}_{\mathrm{i}}+\theta_{\mathrm{i}}+\varepsilon_{\mathrm{it}}$ 
Note that equation (16) allows the parameters of the assimilation curve to vary over time, i.e. there are period effects. For simplicity, the augmentation of skills in the destination, such as education and language ability, are assumed to be duration dependent, and are therefore subsumed under TSM. If unobserved cohort quality varies over time, $\theta$ and TSM will be correlated, in which case OLS estimates of equation (16) will be biased. If unobserved cohort quality is deteriorating over time and there is no statistical control for cohort, then estimates of $\beta$ will tend to be biased upwards. We assume that $\beta$ and $\gamma$ may vary over time, but do not vary by immigrant cohort.

Let $\tau=\mathrm{t}+\mathrm{T}$ where $\mathrm{T}>0$ is the time interval between two longitudinal observations, and $\Delta_{\mathrm{T}}$ denotes the difference operator over $\mathrm{T}$ periods. Equation (16) implies that in time period $\tau$ :

$$
\mathrm{Y}_{\mathrm{i} \tau}=\alpha_{\tau}+\beta_{\tau}\left(\mathrm{TSM}_{\mathrm{it}}+\mathrm{T}\right)-\gamma_{\tau}\left(\mathrm{TSM}_{\mathrm{it}}+\mathrm{T}\right)^{2}+\lambda_{\tau} \mathrm{X}_{\mathrm{i}}+\theta_{\mathrm{i}}+\varepsilon_{\mathrm{i} \tau}
$$

Subtracting equation (17) from equation (16) differences away the specific effect:

$\Delta_{\mathrm{T}} \mathrm{Y}_{\mathrm{i}}=\left(\Delta_{\mathrm{T}} \alpha+\mathrm{T} \beta_{\tau}-\mathrm{T}^{2} \gamma_{\tau}\right)+\left(\Delta_{\mathrm{T}} \beta-2 \mathrm{~T} \gamma_{\tau}\right) \mathrm{TSM}_{\mathrm{it}}-\Delta_{\mathrm{T}} \gamma\left(\mathrm{TSM}_{\mathrm{it}}{ }^{2}\right)+\Delta_{\mathrm{T}} \lambda\left(\mathrm{X}_{\mathrm{i}}\right)+\Delta_{\mathrm{T}} \varepsilon_{\mathrm{i}}$

An obvious advantage of equation (18) over equation (16) is that it does not contain $\theta$, and is therefore not exposed to the effects of potential cohort quality bias. Note that if $\Delta_{\mathrm{T}} \beta=2 \mathrm{~T} \gamma_{\tau}$ and $\Delta_{\mathrm{T}} \gamma=0$, equation (18) says that the longitudinal change in Y over the period is uncorrelated with TSM. In general, however, the signs of the coefficients of $\mathrm{TSM}$ and $\mathrm{TSM}^{2}$ are indeterminate, and they could be positive. If $\left(\Delta_{\mathrm{T}} \beta-2 \mathrm{~T} \gamma_{\tau}\right)>0$ and $\Delta_{\mathrm{T}} \gamma$ $>0$ a $\cap$ - shaped relationship is implied between earnings growth and TSM. This case arises when the earnings assimilation curve becomes steeper and the return to TSM increases. This may create the illusion that the earnings assimilation curve slopes in the "wrong" direction, when all that has happened is that the assimilation curve became steeper.

If the parameters of the model happen to be time invariant, so that $\Delta_{\mathrm{T}} \beta=\Delta_{\mathrm{T}} \gamma=$ $\Delta_{\mathrm{T}} \lambda=0$, equation (18) simplifies to (dropping $\mathrm{t}$ for convenience):

$$
\Delta_{\mathrm{T}} \mathrm{Y}_{\mathrm{i}}=\left(\Delta_{\mathrm{T}} \alpha+\mathrm{T} \beta-\mathrm{T}^{2} \gamma\right)-\delta \mathrm{TSM} \mathrm{i}_{\mathrm{i}}+\Delta_{\mathrm{T}} \varepsilon_{\mathrm{i}}
$$

where $\delta=2 \mathrm{~T} \gamma$, and which implies that the change in the logarithm of earnings over the time interval T varies inversely with TSM in the base period. The parameter $\gamma=\delta / 2 \mathrm{~T}$ is identified in equation (19). So is $\beta$ identified provided that there is extraneous information on $\Delta \alpha$ (e.g. earnings growth of natives). When the parameters are time invariant, $\gamma$ may be estimated using equation (19) or equation (16). 


\subsection{Dynamic Analysis}

Estimates of the earnings assimilation curve from cross-section data are necessarily static. The true earnings assimilation curve may, however, be dynamic. Suppose, for example, that in the true model equation (16) contains a first-order lagged dependent variable with coefficient $0<\phi<1$, which is consistent with a partial adjustment model. The model therefore becomes:

$\mathrm{Y}_{\mathrm{it}}=\alpha_{\mathrm{t}}+\beta \mathrm{TSM}_{\mathrm{it}}-\gamma \mathrm{TSM}_{\mathrm{it}}^{2}+\lambda \mathrm{X}_{\mathrm{i}}+\phi \mathrm{Y}_{\mathrm{it}-1}+\theta_{\mathrm{i}}+\varepsilon_{\mathrm{it}}$

which implies that the long run coefficients of TSM and its square are $\beta /(1-\phi)$ and $-\gamma /(1-$ $\phi)$ respectively. For simplicity we assume that only $\alpha$ varies over time. By repeated substitution it may be shown that:

$$
\begin{aligned}
& \Delta_{T} Y_{i}=\pi_{0}+\pi_{1} T_{S}+\pi_{2} \text {TSM}_{i}^{2}+\pi_{3} X_{i}+\pi_{4} Y_{i}+e_{i} \\
& \text { where } \\
& \pi_{0}=\sum_{t=1}^{T}\left(\alpha_{t}+\beta t-\lambda^{2}\right) \phi^{T-t} \\
& \pi_{1}=\sum_{t=1}^{T}(\beta-2 \gamma t) \phi^{T-t} \\
& \pi_{2}=-\gamma \sum_{t=1}^{T} \phi^{T-t} \\
& \pi_{3}=\lambda \sum_{t=1}^{T} \phi^{T-t} \\
& \pi_{4}=\phi^{T}-1 \\
& e_{i}=\theta_{i} \sum_{t=1}^{T} \phi^{T-t}+\sum_{t=1}^{T} \phi^{T-t} \varepsilon_{i t}
\end{aligned}
$$

Note that all the structural parameters of the model are identified. For example, $\pi_{4}$ identifies $\phi, \pi_{3}$ identifies $\lambda$, etc. The residual error in equation (21) contains the specific effect $\left(\theta_{\mathrm{i}}\right)$, which may be correlated with $\mathrm{Y}_{\mathrm{i}}$. If the earnings of more capable immigrants not only grow faster, but their initial level of earnings is higher, then $\mathrm{E}\left(\mathrm{e}_{\mathrm{i}}, \mathrm{Y}_{\mathrm{i}}\right)>0$, which will tend to bias upwards OLS estimates of $\pi_{4}$. In this event equation (21) should be estimated by IV instead of OLS where the instruments affect the initial level of Y but not its rate of change. 
An alternative interpretation of equation (21) assumes that earnings in the base year are mis-measured, or that "permanent" earnings differ from their transitory counterparts by a random, possibly auto-correlated, error. According to this view there will be regression towards the mean; higher earners in the base year can be expected subsequently to report lower measured earnings growth, and lower earners can be expected to report higher subsequent earnings growth. This implies that $\pi_{4}<0$, which captures regression towards the mean in earnings. For either or both of these reasons (partial adjustment and measurement error) we can expect that the coefficient of $Y_{i}$ in equation (21) will be negative.

\section{The Data}

The data analyzed in this paper derive from three files created by Israel's Central Bureau of Statistics (ICBS) ${ }^{9}$ :
A. the 20 percent sample of the 1983 Census of Population and Housing;
B. the 20 percent sample of the 1995 Census of Population and Housing,
C. a file with matched records of persons in A and B.

The ICBS matched the records of persons who were enumerated in both censuses by means of the Israeli personal identity number (PIN) ${ }^{10}$. In addition, matching to the national Population Register provided information on those who were not enumerated in the 1995 Census because they had either died or had left the country in the interim. From this matched file the persons who were included in the 20 percent samples in both censuses could be identified, potentially a $4 \%$ sample of the 1983 census.

\subsection{Key Variables}

The Population: From files A and B we selected the records of wage-earning Jewish foreign-born men, who had immigrated as adults (at age 18 and over) who were aged 25 to 52 in 1983 and aged 37 to 64 in 1995 (13,682 and 19,558 records respectively), and from file $\mathrm{C}$ the records of men whose wages could be compared in both

\footnotetext{
${ }^{9}$ We are grateful to the Israel Central Bureau of Statistics for making detailed data files available for this research, and to Laura Staetsky who constructed the files which we used.

${ }^{10}$ All permanent residents of Israel are registered in the Population Register of Israel, and identified by a 9 digit PIN. The population register is maintained by the Ministry of Interior and includes records of addresses and demographic and vital events.
} 
censuses, i.e.: who were resident in the country and wage earners at the time of both censuses (1,257 records).

Earnings are for salaried workers and are expressed monthly at September 1995 prices. In 1983 they refer to April ${ }^{11}$ and in 1995 to September.

Time since migration was calculated as the difference between the census year and the year of immigration.

Countries of birth were aggregated into broad groups corresponding to the origins of Jewish immigrants to Israel. The former USSR, the largest source of immigration, is grouped separately. "Western Europe" includes all European countries outside the former Soviet block, including Greece and the Northern countries, but excluding the U.K, which was included among the English speaking countries ("Anglo"). In this group the largest country of origin was France. "Eastern Europe" excludes the former USSR. The largest countries of origin in this group were Poland and Romania. Immigrants originating from African countries were principally from North Africa and Morocco specifically. However, immigrants from Ethiopia, (who arrived mainly in 1985 and 1993), are included in this group in 1995, whereas immigrants from South Africa were included among the English speaking countries. Immigrants from Asia were mainly from the Middle East, the largest countries of origin being Iraq and Iran. The Latin American countries include Mexico, and amongst them Argentina is the largest country of origin. The English speaking countries include the USA, Canada, UK, Australia, New Zealand, South Africa and Zimbabwe.

Labor market experience (exp) is proxied by potential labor market experience as age minus years of schooling minus 5. This measure will over estimate experience for immigrants, who are likely to have suffered interruptions in their employment record, differentially by profession, language skills, and country of origin.

Language proficiency is based on responses to the 1983 Census question: "What language(s) do you speak daily? Do not report a language you know if you do not speak it daily". There are three levels of Hebrew language proficiency (Hebrew is the first or only

\footnotetext{
${ }^{11}$ The early 1980s were a period of economic instability in Israel. The average monthly inflation rate for the four months prior to the census was very high (7.6\%), and for April was $13.3 \%$. In cases where earnings were reported for March or May the data were deflated.
} 
language spoken on a daily basis, Hebrew is the second language spoken, or, the benchmark, Hebrew is not spoken on a daily basis), as well as data on whether the respondents speak English or Arabic on a daily basis as a primary or secondary language.

\subsection{Record Linkage}

The ICBS matched the records of the 1983 Census of Population and Housing with the 1995 Census, in the process identifying persons who had died in Israel between the two censuses or who had left the country (Central Bureau of Statistics, 1999). The matching process was based on the Israeli PIN, but because of possible errors in the PIN in one or both of the censuses a variable indicating matching quality was calculated. This verified the identity of a number of additional personal identifiers beside the PIN, including year and month of birth, sex, religion, year of immigration, country of birth, father's country of birth, and whether the person was ever married. Sixteen levels of identity were determined ranging from total identity to matching PIN only. A small number of additional matches of persons who were left unmatched in the 1995 Census were made based on personal characteristics and membership of identical households in the 1983 and 1995 Censuses. Thus the matching process identifies several groups as shown in Table 1.

It is important to note that an unknown proportion of persons with invalid PINs may have been non-permanent residents of Israel who were enumerated in the census, including foreign workers, clergy, and other temporary residents.

\subsection{Sample Fidelity}

Although the census file is large, the final number of records observable longitudinally is much smaller, and the question arises as to whether it is representative of the initial population. For purposes of the present study not only did records of the two censuses have to be matched, but it was necessary for a person both to be included in the $20 \%$ sample of both censuses and to have wage earnings (with valid income information) in both periods. Since such a wide variety of sources of attrition are possible, it is important to see whether these are selective by duration of residence. Table 2 shows the characteristics of the matched file by sources of attrition and duration of residence. 
The results are consistent with expectations, with death and emigration operating in opposing directions: the likelihood of attrition through death is considerably higher for those with longer durations of residence, whereas the likelihood of emigration is considerably higher for those who immigrated more recently. Since invalid PINs may be due to temporary residence status it is also not surprising that attrition for this reason is more frequent for the recently arrived. All in all, whereas the 1995 Census sampled 20\% of the population overall, due to attrition only $15 \%$ of our 1983 sample was included in the 1995 sample, and of these approximately two thirds were wage earners, 9 percent of the 1983 sample. $^{12}$

\subsection{The Demographic Context}

The ideal economy in which to test IAH would be one in which the immigration stream was constant in size and labor-market related characteristics. Israel is far from this ideal. Immigration to Israel has come in successive waves, which differ from each other in size, in composition by country of origin, in labor market related characteristics (age, marital status, education, language skills, and occupational mix), and in motivation for immigrating. The 1995 Census was held during a wave of immigration reaching scales unprecedented since the establishment of the state in the late 1940s and early 1950s. In the five years preceding the 1995 Census (1990-1994) over 609 thousand immigrants arrived, 85 percent of them from the former USSR. In contrast, only 110 thousand immigrants arrived in the years 1978-1982, of whom approximately a third arrived from the USSR (Central Bureau of Statistics 2002). These immigrations differed not only in size but in the motivations for moving to Israel. The immigrants from the former USSR in the late 1980's and early 1990's had the characteristics of refugees, while in the 1970s and early 1980s immigration was more selective (Paltiel et al, 1997). In addition, immigrant waves differed in their labor market characteristics, in their impact on the local labor market, and consequently, on the relative price of immigrant labor. ${ }^{13}$

In the present context it is important to note that the irregular wave nature of immigration to Israel had consequences for the distribution of the immigrant population in the labor force by time since migration. The following two figures, based on census

\footnotetext{
${ }^{12}$ In practice of the 14,425 foreign-born men who were sampled in 1983, 13,682 had sufficient wage data for analysis, as did 1257 of 1316 individuals in the matched file.

${ }^{13}$ For example, Bahral (1965) shows how the mass immigration in the 1950s affected the level and structure of wages, increasing the rate of return on human capital. See also Beenstock and Fisher (1997).
} 
data, illustrate this. Figure 2 shows the proportion of the labor force that is foreign born by years since migration in 1983 and in 1995. The wave-nature of migration in both periods is apparent, but whereas in 1983 the dominant feature is the wave that arrived in 1949-1952 (over 30 years before), in 1995 the dominant feature is the wave of the early 1990s. Note, however that despite its size it forms a smaller proportion of the labor force than did the earlier wave. Figure 3 shows the same data cumulatively. One sees immediately that in 1995 a smaller proportion of the labor force overall was foreign born, under 40 percent, whereas in 1983 it was well above 50 percent. Moreover, in 1995 the foreign born proportion of the labor force was concentrated at shorter durations: immigrants with 10 years in the country or less formed less than 5 percent of the labor force in 1983, whereas they were over 12 percent of the labor force in 1995. Immigrants who are followed up from 1983 until 1995 were experiencing a substantial change in the nature of the foreign born labor force as a whole.

\section{Empirical Results}

The empirical analysis is conducted for males age 25 to 52 years of age in 1983 (and age 37 to 64 years in 1995) who immigrated to Israel at age 18 or older. Similar results emerge if there is no restriction on age at immigration. Since our priors in favor of IAH were strong, we engaged in extensive specification search when we found that the panel data seemed to reject IAH. Therefore, we failed to corroborate IAH in the panel data despite extensive efforts.

\subsection{Cross Section Analyses: 1983 and 1995}

Table 3 reports the cross-sectional analyses for the 1983 Census and the 1995 Census, following the basic structure of the specification of the immigrant earnings equations found in the literature as in equation (16). That is, the natural logarithm of monthly earnings is regressed on region of birth (Eastern Europe serves as the benchmark), total labor market experience and its square, educational attainment (9 to 12 
years is the benchmark) and marital status, and of course, time since migration (measured in years). In 1983, but not 1995, there are variables for language use. ${ }^{14}$

Three additional variables which are unique to these census data are included in the cross-sectional analysis for 1983 for individuals not linked to the 1995 records. These are whether the 1983 respondent died by 1995, whether he emigrated by 1995, or whether for some other reason (the quality of the link was poor or the PIN was missing or invalid) a link could not be made to the 1995 records.

Table 3 reports two results for 1983 and three for 1995. Model 1 uses all the census data for 1983, while Model 2 only uses the 1983 observations that could be matched to the 1995 Census. Model 3 uses all the census data for 1995, including arrivals after 1983, whereas Model 4 excludes them. Model 5 uses the matched observation in 1995, i.e. the 1995 data for the same observations used in Model 2. Standard results emerge. $^{15}$ In Model 1 earnings increase with educational attainment, total labor market experience, being married, and in the 1983 data, being more proficient in Hebrew, speaking English (by 5 percent) and not speaking Arabic (by 5 percent). There are no significant differences in earnings from those of the benchmark (Eastern European immigrants) on the part of those from Western Europe, the English-speaking countries (ANGLO) or Latin America, but those from Asia and Africa have about 20 percent lower earnings in the full cross-sectional data, and those from the former Soviet Union (USSR) have five percent lower earnings in 1983 (controlling for Hebrew language skills) but 15 percent lower earnings (Model 3) in 1995 (no control for language skills), which declines to ten percent lower earnings if post-1983 immigrants are deleted (Model 4). The latter reflects the very low earnings in 1995 of the newly arrived immigrants from the former USSR and their limited proficiency in Hebrew.

If the 1995 matched observations were not a selected subset of the 1983 sample, then the death, emigration and badlink variables in the analysis of 1983 earnings would have coefficients that are not statistically significant. This is not the case according to Model 1. Immigrants who died between 1983 and 1995, other measured variables being the same, had significantly lower (12 percent) earnings. The shadow of death was upon them! This suggests they were in poorer health and in 1983 either worked fewer hours per month or had a lower hourly wage or both. There was no significant difference in

\footnotetext{
${ }^{14}$ There were no questions on language in the 1995 Census.

${ }^{15}$ The results of Model 1 are consistent with those obtained by Chiswick (1995) using the same data.
} 
earnings for those who emigrated between 1983 and 1995 (an insignificant coefficient of one percent). This suggests that on balance there was no selectivity in the unmeasured characteristics that relate to labor market earnings among immigrants who left Israel during the 12-year period. ${ }^{16}$ However, earnings among those who could not be matched to the 1995 Census, primarily because of bad ID numbers, were nearly 6 percent lower. This significant difference occurs even after controlling for variables that might influence the degree to which there are errors in reporting the ID number, such as educational attainment and proficiency in Hebrew. These results for death and badlink suggest that there is favorable selectivity in terms of labor market earnings in the 1983 observations that "survived" to the 1995 matched file, literally in terms of the death variable and figuratively in terms of the correct matching.

In the 1983 and 1995 data earnings increase at a decreasing rate with duration of residence in Israel. The effect is smaller in the 1983 Census than in the 1995 data. Evaluated at 10 years, earnings increase by about 2.2 percent per year in 1983 , in contrast to about 4.0 percent in the full 1995 data, and even by 2.8 percent for those who immigrated in 1983 or earlier. Thus, the partial effect of time since migration in Israel had almost doubled between 1983 and 1995.

Models 2 and 5 in Table 3 are estimated for 1983 for immigrants age 18 years or older and who were matched in the 1983 and 1995 Censuses. The patterns observed in the full cross-sections are also found in the separate year-specific cross-sections for the matched samples. The primary differences are the lack of statistical significance of the total labor market experience variable in the 1995 matched sample, all of whom had been in Israel at least 12 years, and the very low earnings in 1995 of the very small sample of matched men without any schooling (EDO).

\subsection{Pooled Cross Sections: Synthetic Cohorts}

In Table 4 cross-sectional data from the 1983 Census and from the 1995 Census are pooled and the regressions computed with the natural logarithm of monthly earnings as the dependent variable and the explanatory variables are the variables used above that are common to both data sets. Model 1 in Table 4 includes a dummy variable for 1983, while Model 2 includes this variable and its interaction with duration in 1983. Model 1

\footnotetext{
${ }^{16}$ If given their measured characteristics the least (most) successful left, the coefficient would have been negative (positive).
} 
applies the synthetic cohort methodology proposed by Borjas (1985) in which the census dummy for 1983 captures cohort quality and wage growth between 1983 and 1995 . Native wage growth during this period was $12.6 \%$. In the absence of cohort effects we therefore expect the coefficient of the census dummy to be -0.12 . If, however, earlier immigrant cohorts were superior, the coefficient of the census dummy should be greater than -0.12 . In fact, this coefficient turns out to be 0.018 and is marginally significant, suggesting that earlier immigrant cohorts' productivity was on average about $14 \%$ higher. The coefficients on TSM and its square imply that during the first 10 years immigrant earnings grow by an average of $4.2 \%$ per year.

The synthetic cohort specification in Model 1 restricts the assimilation curve to have the same shape in 1995 and 1983. It also restricts other coefficients, such as those on demographic controls to be the same in both years. It should be obvious from Table 3 that these restrictions are incorrect. To make this point yet clearer in Model 2 we allow the assimilation curve to vary between 1983 and 1995 by interacting the census dummy with TSM and its square. Both of these terms are statistically significant confirming the result in Table 3 that the assimilation curve steepened. Note also that the census dummy is now clearly statistically significant and positive, implying that not only did the assimilation curve steepen but its intercept in 1995 was about 23\% below what it was in 1983. In 1995 immigrants started out at a greater wage disadvantage than they did in 1983.

\subsection{Longitudinal Data}

Table 5 takes advantage of the panel nature of the matched data to examine two related dependent variables, the change in the natural logarithm of earnings in Models 1 and 2, and the percentage change in earnings in Models 3 and 4.We report both results because the change in logs over a 12-year period may be a poor proxy for the percentage change. Models 1 and 3 estimate equation (20). Models 2 and 4 condition on the level of earnings in 1983, as in equation (23). The other variables take their 1983 values.

Model 1 in Table 5 estimates equation (20). None of the variables in the model turned out to be even remotely statistically significant. This is true for the demographic controls as well as for TSM and its square. Indeed, the F statistic indicates that the change in log earnings between 1983 and 1995 seems to be entirely random. Model 3 shows that the same applies when the dependent variables is expressed as a percentage change. Using equation (20) to interpret these findings implies that $\Delta_{\mathrm{T}} \beta=2 \mathrm{~T} \gamma_{1}, \Delta_{\mathrm{T}} \gamma=0$, and $\Delta_{\mathrm{T}} \lambda$ 
$=0$. The former implies that the change in $\beta$ just happened to equal $24 \gamma$. The second implies that $\gamma$ did not change. The latter implies that the coefficients of the demographic controls did not change between 1983 and 1995. In short, the assimilation curve steepened between 1983 and 1995 because $\beta$ increased. This result is, of course, consistent with Tables 3 and 4.

Matters turn out to be quite different when equation (23), the dynamic assimilation model, is estimated as in Models 2 and 4 in Table 5. Earnings in 1983 have a highly significant negative effect on the change in earnings from 1983 to 1995 . Using the specification for the difference in the natural logarithm of earnings, Model 2 in Table 5 estimates $\pi_{4}$ at -0.5676 , which, using the definitions given with equation (23), implies that $\phi=0.9325$. This is the first-order mean reversion coefficient for earnings. The elasticity of earnings in 1995 with respect to 1983 earnings is $1+\pi_{4}=0.43 .{ }^{17}$ That is, earnings are higher in 1995 for those with higher earnings in 1983, other 1983 measure variables the same, but the relative gap has narrowed. Those who had lower earnings in 1983, perhaps because of a lower transferability of skill when other measured variables are held constant or greater foregone earnings because of greater investment in human capital, had a relatively steeper rise in earnings over the 12-year period. This negative relation between initial earnings and the steepness of earnings growth is consistent with the immigrant assimilation hypothesis (Chiswick 1978, 1979).

Model 2 in Table 5 shows that duration matters. Earnings increased faster over the 12- year period for immigrants who had been longer in Israel as of 1983. An extra year in Israel increased the growth rate in earnings from 1983 to 1995 by 0.0273 2(0.0006)xTSM, or for a person who immigrated in 1973 (TSM=10) by 1.5 percentage points. This may be reflecting the return to greater Israel-specific human capital. Among those who immigrated as adults, and who are in the destination over 12 years, one would not expect any further gains from the acquisition of addition local human capital. Therefore, the fact that their earnings are growing is consistent with an increasing return to the local human capital that they have already acquired. ${ }^{18}$

\footnotetext{
${ }^{17}$ The specification in Model 1 in Table 5 restricts the elasticity of earnings in 1995 with respect to earnings in 1983 to be unity, other measured variables the same. The estimated elasticity, however, of 0.43 is significantly lower than unity.

${ }^{18}$ The dynamic assimilation model (Table 5, models 2 and 4) also suggests an increase in the rate of return from schooling among the immigrants. In the matched pairs, the effect of education on earnings for those with 13 or more years, compared to those with 9 to 12 years of schooling, increased significantly over the 12 year period in both the change in log earnings and percent change in earnings specifications. The effect of schooling on earnings also increased for men born in Israel. In cross-sectional equations the coefficient
} 
Model 2 estimates $\pi_{2}$ at -0.0006 , which using the definitions below equation (23) implies $\gamma=0.00081$, and it estimates $\pi_{1}$ at 0.0273 , which implies $\beta=0.0048$. Since $\phi=$ 0.9325 the derived long run coefficients on TSM and its square are 0.0711 and -0.0120 respectively. These coefficients imply a much steeper assimilation curve than the static estimates reported in Tables 3 and 4 . They imply that during the first 10 years immigrant earnings grow by $6 \%$ per year, which is substantially larger than their counterparts in Tables 3 and 4 . These comparative results suggest, not surprisingly, that if the assimilation process is dynamic, it will be difficult to estimate it using cross-section data.

Almost all of the demographic controls used to estimate Model 2 in Table 5 are not statistically significant, implying that the $\pi_{3}$ coefficients in equation (23) and the $\lambda$ coefficients in equation (22) tend to be zero, with the exception of immigrants with more than 13 years of schooling. Earnings growth over the period was greater for those with at least some university-level education, compared to the benchmark of 9 to 12 years of schooling. This reflects the increase in the rate of return from schooling.

A static assimilation model with a quadratic effect of duration on earnings would imply a slower growth in wages over the 12-year period the longer the immigrant was in Israel in 1983. A dynamic assimilation model that allows the effect on earnings of local or destination specific skills to vary over time offers no such simple prediction. If the return to these skills increases over time (as was the situation in Israel in this period) the duration-earnings profile observed in the cross-section becomes steeper, the relative earnings of immigrants with few of these skills would decline, and the rise in earnings in longitudinal data may be greater, rather than smaller, for immigrants with a longer duration in the destination. If the rate of return on destination skills were to fall over time, however, comparisons of cross-sectional profiles would show a decline in the slope of the duration-earnings profile and the longitudinal data would show smaller (perhaps negative) earnings growth for those with longer durations, compared to a situation in which the return to these skills is unchanged.

\subsection{Survivor Bias}

In Sections 1 and 2 we conjectured that survivor bias might account for contradictions between results obtained from synthetic cohorts and results obtained using panel data. Evidence in favor of the hypothesis that survivors are fitter may be found in

on 13 or more years of schooling in Israel increased from 0.36 to 0.43 from 1983 to 1995 , compared to men with 9 to 12 years of schooling. 
Model 1 in Table 3. Although re-migrants seemed to be neutrally selected on earnings, immigrants who died by 1995 earned 12 percent less in 1983, suggesting a positive return to fitness and survivorship. To investigate this matter further we carried out the following exercises. In Model 2 in Table 3 we control for immigrants who earned in 1995. We found that immigrants who also earned in 1995 already had a 12.2 percent wage premium in 1983, suggesting a positive return to survivorship in the labor market. Next, we estimated Model 5 in Table 3 controlling for having earned in 1983. We found that immigrants in 1995 had a wage premium of 19 percent if they also earned in 1983.

These results suggest, perhaps not surprisingly, that survivors earn more. They also suggest that SCM, which by definition cannot control for survivorship, might contain survivor bias. Earners observed say in 1990 cannot be compared with their would-be counterparts in 1980 because the survivors in 1990 have higher average fitness than their counterparts in 1980. Therefore SCM estimates of assimilation are most probably biased upwards. Indeed, if there are no period effects, corroboration of IAH by SCM and its rejection by panel data would lead to the conclusion that SCM confounds survivor bias and assimilation.

Following Juhn, Murphy and Pierce (1993) we measure within-group wage inequality by residuals from wage regressions. Using the residuals from Model 3 in Table 3 we find that within-group wage inequality in 1995 varied directly with duration. This suggests that it takes time for the fitness of immigrants to be appropriately priced in the labor market. This finding too is consistent with our conjecture about survivor bias. However, a similar exercise carried out in 1983 using the residuals of Model 1 in Table 3 comes up with the opposite result, i.e. within-group wage inequality varies inversely with duration.

The 1,257 immigrants used to estimate the models in Table 5 had to remain alive and be in Israel in 1995, and they had to be earning in 1983 and 1995. If these immigrants are positively/negatively selected the estimates of earnings growth in Table 5 will be over/under-estimated. In the absence of convincing instruments to determine survivorship (i.e. instruments that affect survivorship but which do not directly affect earnings growth), we followed Horowitz and Manski (1998) and calculated non-parametric bounds for attrition bias. The width of these bounds naturally increases with the gap between the highest and lowest earnings in 1995. Since the latter is very large the non-parametric bound to the effect of attrition is very large too. We cannot rule out, for example, that immigrant earnings fell considerably between 1983 and 1995. 


\section{Summary and Conclusions}

Conventional analysis of a new panel data set for Israel on adult male immigrant earnings in 1983 and 1995 does not support the Immigrant Assimilation Hypothesis, which predicts that the earnings growth for immigrants should vary inversely with duration in 1983. This apparent rejection of IAH joins at least two other recent empirical studies, which used longitudinal data, and which failed to corroborate IAH in Canada (Hum and Simpson, 2000, 2004a) and in the US (Hu 2000). By contrast synthetic cohort data universally support IAH. This contradiction between evidence from synthetic cohort and genuine cohort data is also true in Israel.

We suggest two possible explanations for resolving the contradiction. First, SCM is more prone to survivor bias than panel data. Therefore corroboration of IAH by SCM can be a statistical illusion induced by survivor bias. We were in the unusually fortunate position of being able to identify the sources of survivor bias because we had access to administrative records on individuals who were observed in 1983 but were not observed in 1995. We used these data to investigate the nature of survivor bias. We found a positive return to survivorship. Immigrants with the "shadow of death" upon them earn less, that is, those who died between 1983 and 1995 earned less in 1983. However, immigrants who subsequently left Israel did not earn less in 1983. Reasons for not surviving seem to matter for immigrant earnings.

Furthermore there is evidence of survivor bias in the labor market itself. Workers in 1983 who also worked in 1995 earned more than workers who withdrew from the labor force after 1983, or entered it by 1995. Therefore, earnings may appear to grow according to SCM simply as an artifact of survivor bias. The earnings in 1995 are higher simply because the immigrant workers observed in 1995 are "fitter" and not because they are more assimilated.

The second explanation maintains that period effects obscure the true assimilation curve, which changes shape over time. Indeed, period effects can create the misleading impression that IAH is false when it is true, and vice-versa. If the return to destinationspecific skills increases, this creates the impression that the assimilation effect has weakened. Indeed, under special conditions it may disappear altogether. If there is no reason to suspect that the return to destination-specific skills increased sufficiently, and therefore that there are no period effects, we must presume that the panel results correctly falsify IAH, and therefore that SCM misleads. 
However, there is reason to suspect that the return to destination-specific skills may have increased in Israel. As mentioned in the theory above (Section 3.2), mass immigration to Israel in the years preceding 1995 may have raised the demand for incumbent immigrant labor, thereby increasing the return to their destination-specific skills. This could have induced period effects creating a partial or even total eclipse of the true assimilation effect.

These results suggest that the estimation of immigrant assimilation effects is far more complex than earlier research would have suggested. In addition to the problems previously identified in the use of cross-sectional and synthetic cohort analysis, this paper demonstrates that issues of survivor bias and period effects, which may be endogenous to the effects of the immigration on the labor market, raise serious challenges to the analysis of panel data from longitudinal surveys and censuses. 
Table 1. Sources of Attrition

\begin{tabular}{|l|l|}
\hline Total 1983 Census File & $100.0 \%$ \\
\hline $\begin{array}{l}\text { 1. records in both censuses which have been reliably } \\
\text { matched }\end{array}$ & $74.5 \%$ \\
\hline $\begin{array}{l}\text { 2. records which have been matched by PIN but the } \\
\text { identity is uncertain }\end{array}$ & $3.7 \%$ \\
\hline $\begin{array}{l}\text { 3. records of persons enumerated in 1983 who had died } \\
\text { before the 1995 census }\end{array}$ & $7.6 \%$ \\
\hline $\begin{array}{l}\text { 4. records of persons enumerated in 1983 who had left } \\
\text { the country before the1995 census }\end{array}$ & $2.4 \%$ \\
\hline $\begin{array}{l}\text { 5. records of persons whose PIN in 1983 was not valid } \\
\text { and therefore could not be matched }\end{array}$ & $3.9 \%$ \\
\hline $\begin{array}{l}\text { 6. records of persons with valid PINs who did not find a } \\
\text { match in 1995, either because of census undercoverage, } \\
\text { misidentification of emigration or technical quality of the } \\
\text { 1995 census. }\end{array}$ & $7.2 \%$ \\
\hline
\end{tabular}

Table 2 Attrition and Time Since Migration

(Foreign Born Jewish Males aged 25-52 in the 1983 Census who immigrated at age $18+)$

\begin{tabular}{|c|c|c|c|c|c|c|c|c|c|}
\hline \multirow{2}{*}{$\begin{array}{l}\text { Years since } \\
\text { immigration }\end{array}$} & \multirow[t]{2}{*}{$\mathbf{N}$} & \multirow{2}{*}{$\begin{array}{l}\text { Linked } \\
\text { well }\end{array}$} & \multirow{2}{*}{$\begin{array}{c}\text { Died } \\
\text { before } \\
1995 \\
\text { census }\end{array}$} & \multirow{2}{*}{$\begin{array}{l}\text { Emigrated } \\
1983-1995\end{array}$} & \multirow{2}{*}{$\begin{array}{l}\text { Link } \\
\text { quality } \\
\text { poor }\end{array}$} & \multirow{2}{*}{$\begin{array}{c}\text { Invalid } \\
\text { PIN }\end{array}$} & \multirow{2}{*}{\begin{tabular}{|c|} 
Sampled \\
in 1995
\end{tabular}} & \multicolumn{2}{|c|}{ Employed in 1995} \\
\hline & & & & & & & & percentage & $\mathbf{N}$ \\
\hline Total & $14,425100 \%$ & $79 \%$ & $5 \%$ & $5 \%$ & $3 \%$ & $9 \%$ & $15 \%$ & $9 \%$ & 1316 \\
\hline $0-4$ & $1,711100 \%$ & $68 \%$ & $3 \%$ & $10 \%$ & $2 \%$ & $17 \%$ & $12 \%$ & $9 \%$ & 147 \\
\hline $5-9$ & $2,485100 \%$ & $76 \%$ & $3 \%$ & $10 \%$ & $2 \%$ & $9 \%$ & $15 \%$ & $9 \%$ & 232 \\
\hline $10-14$ & $3,490100 \%$ & $81 \%$ & $4 \%$ & $6 \%$ & $2 \%$ & $8 \%$ & $17 \%$ & $10 \%$ & 349 \\
\hline $15-19$ & $1,729100 \%$ & $82 \%$ & $5 \%$ & $3 \%$ & $3 \%$ & $7 \%$ & $16 \%$ & $10 \%$ & 179 \\
\hline $20-24$ & $2,046100 \%$ & $83 \%$ & $5 \%$ & $1 \%$ & $4 \%$ & $7 \%$ & $15 \%$ & $9 \%$ & 188 \\
\hline $25+$ & $2,366100 \%$ & $80 \%$ & $9 \%$ & $1 \%$ & $4 \%$ & $7 \%$ & $16 \%$ & $7 \%$ & 221 \\
\hline
\end{tabular}


Table 3. Cross-Section Results: Estimates of Equation (16)

Dependent Variable: $\log$ (earnings)

Foreign Born Males aged 25 - 52 in 1983 and 37 - 64 in 1995 Aged 18+ at Immigration

\begin{tabular}{|c|c|c|c|c|c|c|c|c|c|c|}
\hline & \multicolumn{4}{|c|}{1983} & \multicolumn{6}{|c|}{1995} \\
\hline & \multicolumn{2}{|c|}{ Model 1} & \multicolumn{2}{|c|}{ Model 2} & \multicolumn{2}{|c|}{ Model 3} & \multicolumn{2}{|c|}{ Model 4} & \multicolumn{2}{|c|}{ Model 5} \\
\hline & \multicolumn{2}{|c|}{ Census $^{(a)}$} & \multicolumn{2}{|c|}{ Matched } & \multicolumn{2}{|c|}{ Census (All) } & \multicolumn{2}{|c|}{$\begin{array}{l}\text { Census (Arrived by } \\
1983 \text { ) }\end{array}$} & \multicolumn{2}{|c|}{ Matched } \\
\hline & $\beta$ & P-value & $\beta$ & $\mathrm{P}$-value & $\beta$ & $\mathrm{P}$-value & $\beta$ & P-value & $\beta$ & P-value \\
\hline Intercept & 7.23546 & $<.0001$ & 7.305 & $<.0001$ & 7.8064 & $<.0001$ & 7.4724 & $<.0001$ & 7.778 & $<.0001$ \\
\hline USSR & -0.0437 & 0.0178 & 0.0277 & 0.5560 & -0.1514 & $<.0001$ & -0.0964 & $<.0001$ & 0.0127 & 0.8819 \\
\hline WEURO & 0.0482 & 0.1147 & 0.0931 & 0.2579 & -0.1063 & 0.0012 & -0.1488 & 0.0003 & -0.0375 & 0.7956 \\
\hline ANGLO & 0.00447 & 0.8966 & 0.0165 & 0.8549 & 0.0687 & 0.0063 & -0.0402 & 0.2252 & 0.04841 & 0.6929 \\
\hline LAMER & -0.0215 & 0.4155 & -0.0770 & 0.2364 & -0.0146 & 0.5618 & -0.0339 & 0.2838 & -0.0744 & 0.4911 \\
\hline AFRICA & -0.1787 & $<.0001$ & -0.1429 & 0.0019 & -0.2198 & $<.0001$ & -0.13815 & $<.0001$ & -0.0445 & 0.5976 \\
\hline ASIA & -0.1845 & $<.0001$ & -0.1570 & 0.0018 & -0.2134 & $<.0001$ & -0.1554 & $<.0001$ & -0.1713 & 0.0660 \\
\hline EXP & 0.0277 & $<.0001$ & 0.0242 & 0.0012 & -0.0050 & 0.1039 & 0.0063 & 0.2826 & -0.0075 & 0.7265 \\
\hline $\mathrm{EXP}^{2}$ & -0.0006 & $<.0001$ & -0.0005 & 0.0013 & -0.0002 & 0.0003 & -0.0003 & 0.0013 & -0.0000 & -0.8751 \\
\hline ED0 & -0.2868 & $<.0001$ & -0.28214 & 0.0021 & -0.1888 & $<.0001$ & -0.2868 & $<.0001$ & -0.7390 & $<.0001$ \\
\hline ED1-8 & -0.2204 & $<.0001$ & -0.2588 & $<.0001$ & -0.1876 & $<.0001$ & -0.2393 & $<.0001$ & -0.2575 & 0.0042 \\
\hline ED13+ & 0.4098 & $<.0001$ & 0.4319 & 0.0001 & 0.2693 & $<.0001$ & 0.4910 & $<.0001$ & 0.4240 & $<.0001$ \\
\hline Married & 0.3681 & $<.0001$ & 0.2989 & 0.0001 & 0.3199 & $<.0001$ & 0.4838 & $<.0001$ & 0.2824 & 0.1652 \\
\hline Died & -0.1221 & $<.0001$ & & & & & & & & \\
\hline Emig & 0.0103 & 0.6848 & & & & & & & & \\
\hline Badlink & -0.0565 & 0.0026 & & & & & & & & \\
\hline Hebfirst & 0.1209 & $<.0001$ & 0.1550 & 0.0061 & & & & & & \\
\hline Hebsecon & 0.0794 & 0.0003 & 0.0634 & 0.2599 & & & & & & \\
\hline English & 0.0589 & 0.0264 & 0.1131 & 0.0880 & & & & & & \\
\hline Arabic & -0.0523 & 0.0040 & -0.1273 & 0.0065 & & & & & & \\
\hline TSM & 0.0282 & $<.0001$ & 0.02913 & $<.0001$ & 0.0543 & $<.0001$ & 0.0361 & $<.0001$ & 0.0410 & 0.0418 \\
\hline $\mathrm{TSM}^{2}$ & -0.0004 & $<.0001$ & -0.0004 & 0.0527 & -0.0007 & $<.0001$ & -0.0004 & $<.0001$ & -0.0005 & 0.1203 \\
\hline $\mathrm{R}^{2}$ & 0.2250 & & 0.2601 & & 0.2978 & & 0.2484 & & & \\
\hline $\mathrm{N}$ & 13682 & & 1982 & & 19558 & & 8612 & & 1982 & \\
\hline
\end{tabular}

(a) 1983 income adjusted to 1995 prices. Intercept unadjusted is 9.28341

Source: 1983 and 1995 Censuses of Israel, 20 percent microdata files. 
Table 4. Synthetic Cohort Results: Pooled 1983 and 1995 Census data: Foreign Born Males aged 25 - 52 in 1983: immigrated at Age 18+

\begin{tabular}{|l|l|l|l|l|}
\hline \multirow{2}{*}{} & \multicolumn{4}{|c|}{ Dependent Variable Log Earnings } \\
\cline { 2 - 5 } & Model 1 & \multicolumn{2}{l|}{ Model 2 } \\
\hline & \multicolumn{1}{|c|}{$\beta$} & P-value & \multicolumn{1}{c|}{$\beta$} & P-value \\
\hline Intercept & 7.4472 & $<.0001$ & 7.4080 & $<.0001$ \\
\hline USSR & -0.0975 & $<.0001$ & -0.0999 & $<.0001$ \\
\hline WEURO & 0.0228 & 0.2843 & 0.0118 & 0.5805 \\
\hline ANGLO & 0.0954 & $<.0001$ & 0.0747 & $<.0001$ \\
\hline LAMER & 0.0502 & 0.0354 & 0.0240 & 0.3168 \\
\hline AFRICA & -0.2237 & $<.0001$ & -0.2119 & $<.0001$ \\
\hline ASIA & -0.2041 & $<.0001$ & -0.2062 & $<.0001$ \\
\hline EXP & 0.0194 & $<.0001$ & 0.0199 & $<.0001$ \\
\hline EXP2 & -0.0005 & $<.0001$ & -0.0005 & $<.0001$ \\
\hline ED 0 & -0.2293 & $<.0001$ & -0.2246 & $<.0001$ \\
\hline ED1-8 & -0.2071 & $<.0001$ & -0.2005 & $<.0001$ \\
\hline ED13+ & 0.3200 & $<.0001$ & 0.3175 & $<.0001$ \\
\hline Married & 0.2717 & $<.0001$ & 0.2714 & $<.0001$ \\
\hline in1983 & 0.0181 & 0.0303 & 0.2041 & $<.0001$ \\
\hline Died & -0.1170 & $<.0001$ & -0.1096 & $<.0001$ \\
\hline Emig & 0.0327 & 0.1697 & 0.0010 & 0.9661 \\
\hline Badlink & -0.0560 & 0.0013 & -0.0720 & $<.0001$ \\
\hline in83* TSM & & & -0.0223 & $<.0001$ \\
\hline in83* TSM2 & & & 0.0004 & $<.0001$ \\
\hline TSM & 0.0488 & $<.0001$ & 0.0539 & $<.0001$ \\
\hline TSM2 & -0.0007 & $<.0001$ & -0.0008 & $<.0001$ \\
\hline R2 & 0.2398 & & 0.2430 & \\
\hline F & 581.65 & & 532.79 & \\
\hline N & 33,213 & & 33,213 & \\
\hline & & & & \\
\hline
\end{tabular}

Source: 1983 and 1995 Censuses of Israel, 20 percent microdata files. 
Table 5. Panel Results: Estimates of Equation (18) and (21)

Foreign born males aged 25 - 52 in 1983: immigrated at Age 18+

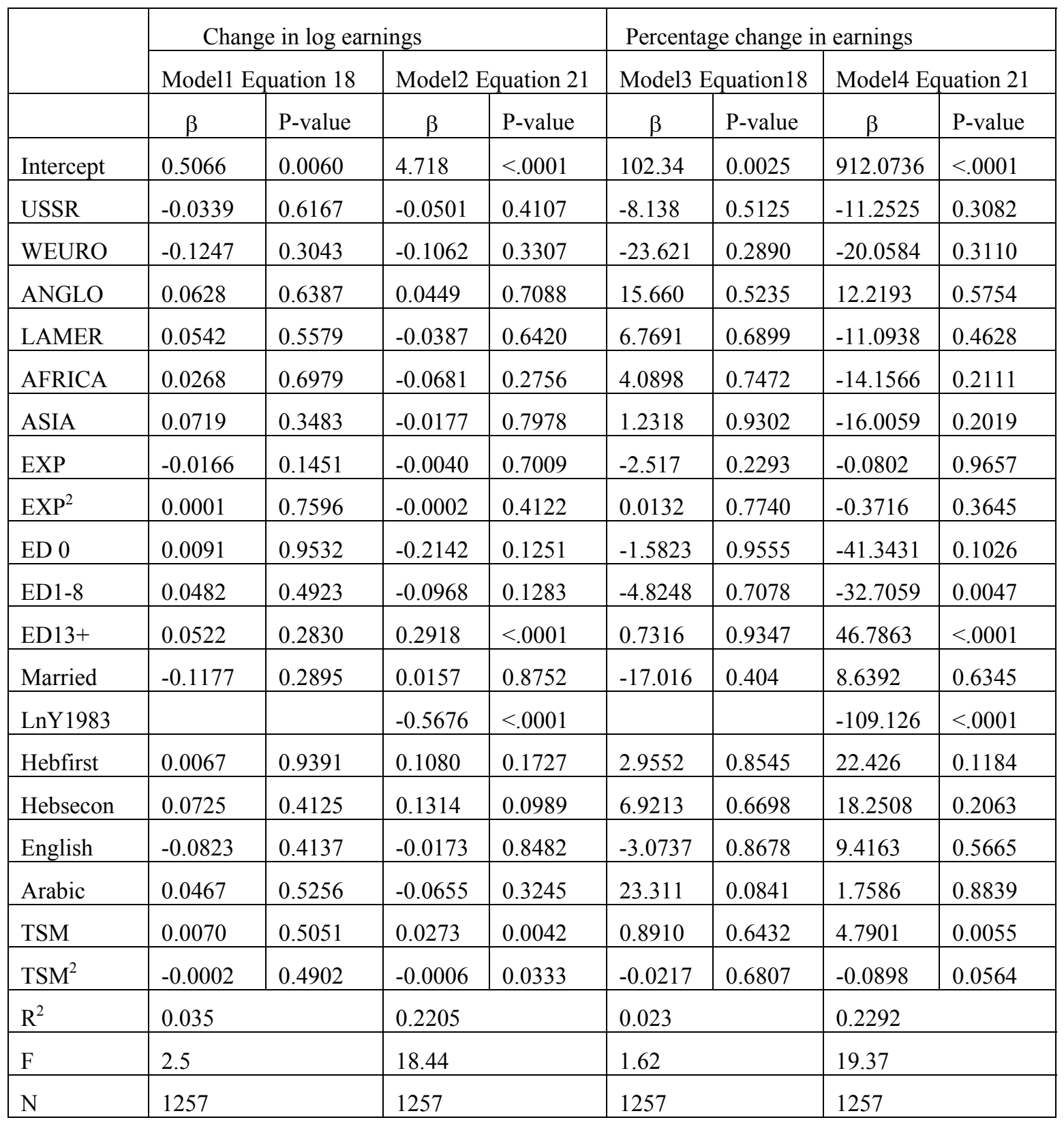

Source: Matched sample from 1983 and 1995 Censuses of Israel, 20 percent microdata files. 
Figure 1. The Assimilation Curve

Figure 1. The Assimilation Curve

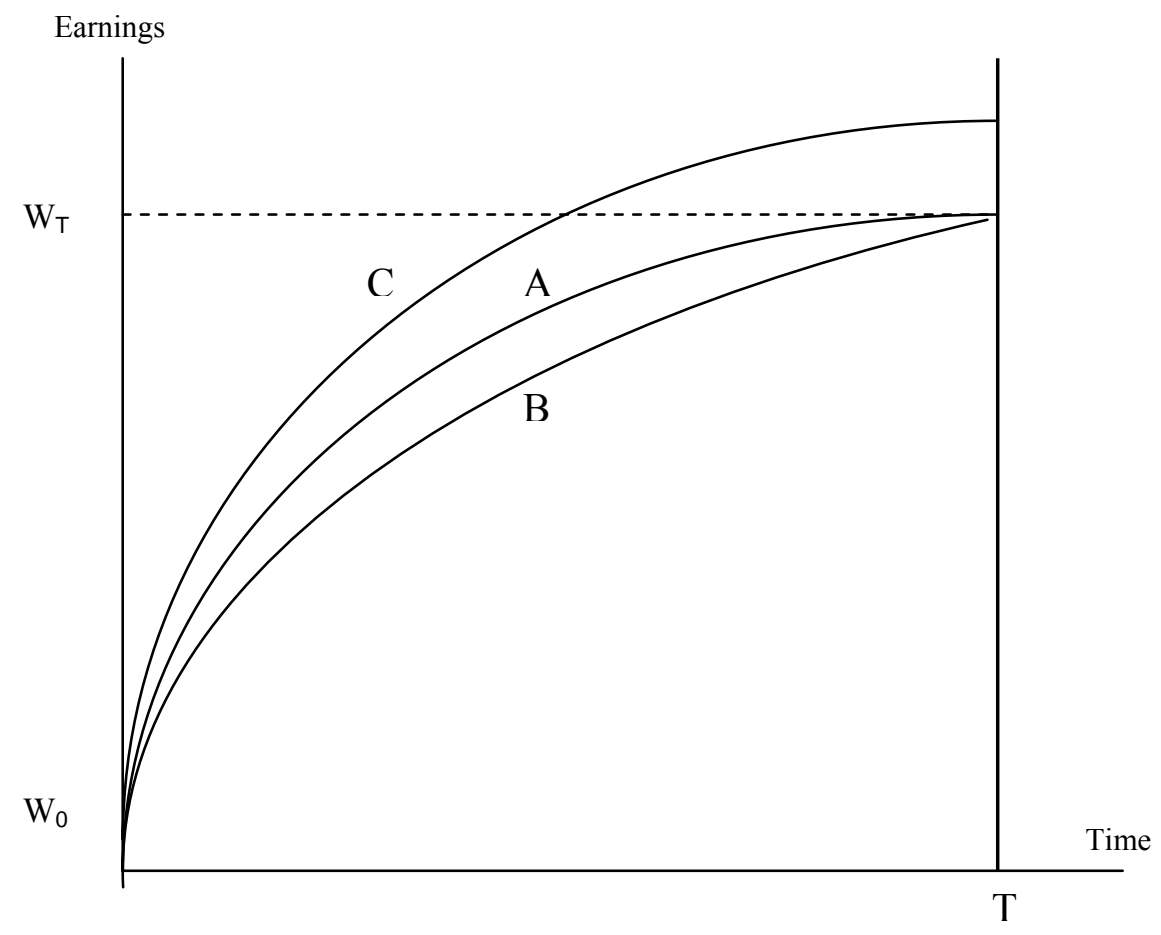

Figure 2. Foreign-born percentage of Labor Force by TSM, 1983 and 1995

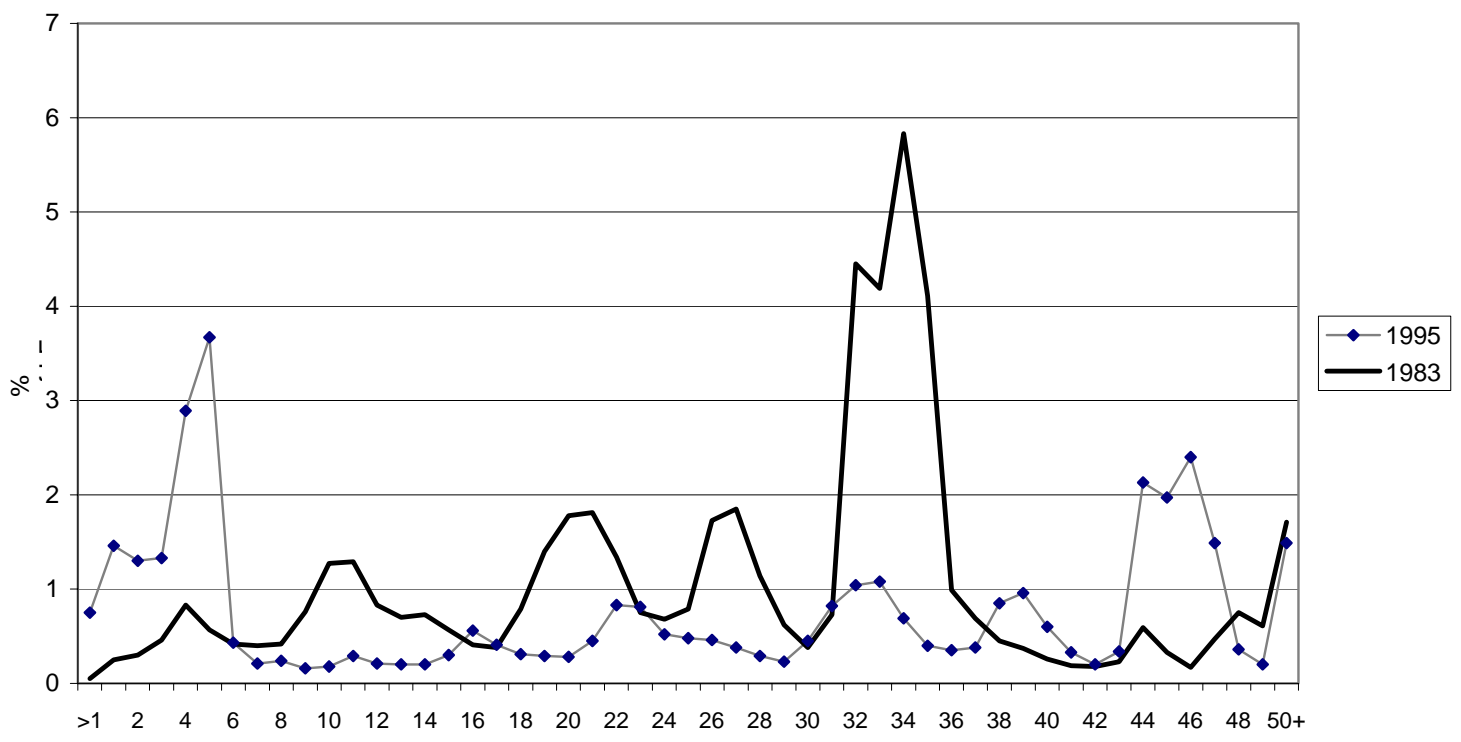


Figure 3. Cumulative Foreign-born percentage of Labor force by TSM, 1983 and 1995

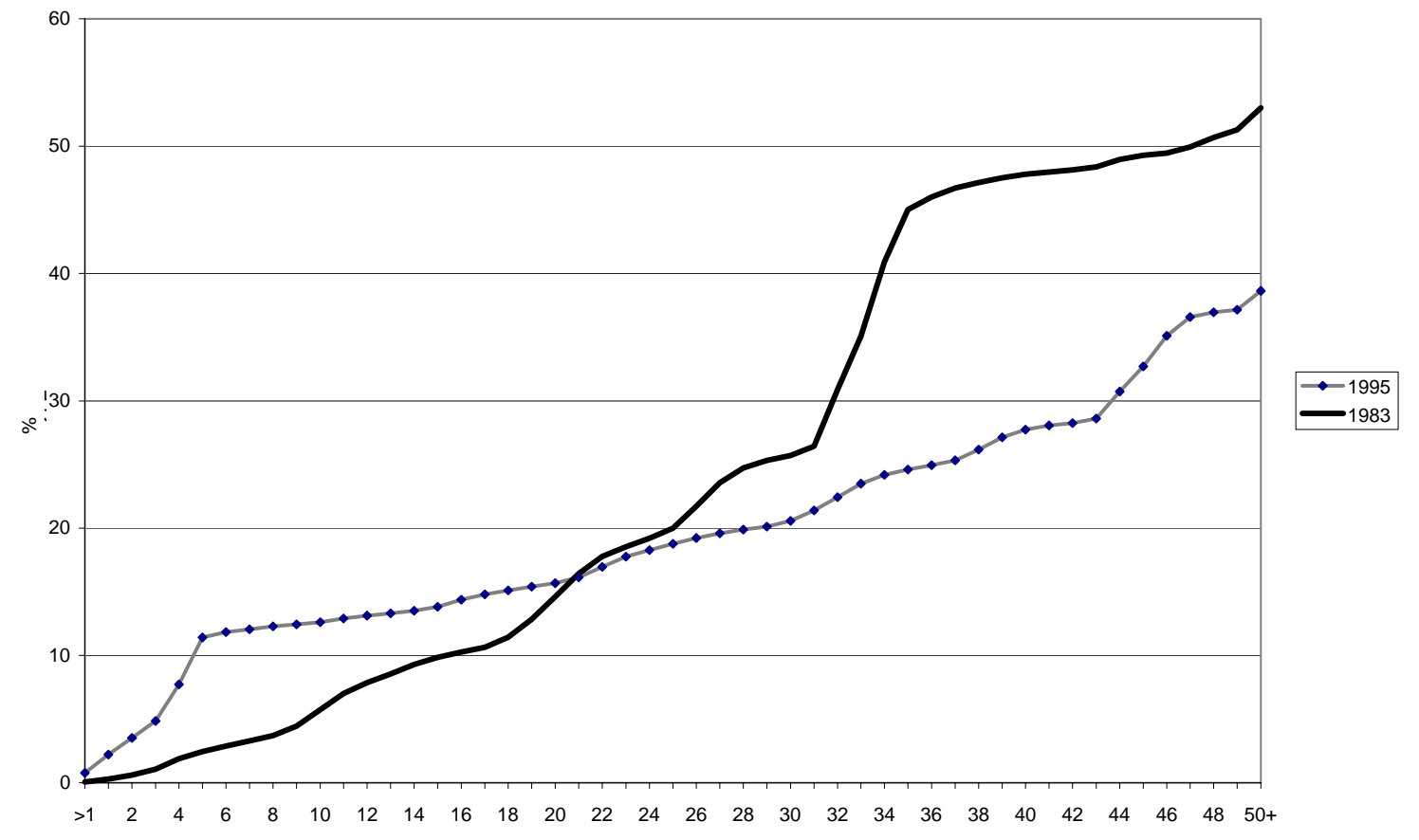




\section{References}

Bahral, Uri (1965) The effects of mass migration on wages in Israel, Jerusalem: Falk Project for Economic Research in Israel.

Beenstock M. (1996) Failure to absorb: remigration by immigrants into Israel, International Migration Review, 30: 950-78.

Beenstock M. and J. Fisher (1997) The macroeconomic effects of immigration: Israel in the 1990s. Review of World Economics, 133: 330-358.

Beenstock M., B.R. Chiswick and G. Repetto (1991) The effect of linguistic distance and country of origin on immigrant language skills: an application to Israel, International Migration, 39: 33-60.

Black R., T. Fielding, R. King, R. Skeldon and R. Tiemoko (2003) Longitudinal studies: an insight into current studies and the social and economic outcomes for immigrants, Working Paper 14, Sussex Centre for Migration Research, University of Sussex.

Borjas G.S. (1985) Assimilation, changes in cohort quality, and the earnings of immigrants, Journal of Labor Economics, 3: 463-89.

Borjas G.S. (1989) Immigrant and emigrant earnings: a longitudinal study, Economic Inquiry, 27: 21-37.

Central Bureau of Statistics (1999) Documentation of the matching process of the 1983 and 1995 Censuses, 30.121999 (Hebrew only), internal memorandum.

Central Bureau of Statistics (2002) Immigration to Israel 1999, Jerusalem, Central Bureau of Statistics Publication No. 1173.

Chiswick B.R. (1978a) A longitudinal analysis of the occupational mobility of immigrants," in Barbara D. Dennis, ed., Proceedings of the 30th Annual Winter Meetings, Industrial Relations Research Association, Madison, I.R.R.A., pp. 20-27.

Chiswick B.R. (1978b) The effect of americanization on the earnings of foreign-born men, Journal of Political Economy, 86(5), October,:897-922.

Chiswick B.R. (1979) The economic progress of immigrants: Some apparently universal patterns. In William Fellner, ed., Contemporary Economic Problems, 1979, Washington: American Enterprise Institute, pp. 357-399.

Chiswick B.R. (1980) An analysis of the economic progress and impact of immigrants, Report Prepared for the Employment and Training Administration, U.S. Department of Labor. National Technical Information Service, August 1980, PB80-200454, 1980, 410 pp. 
Chiswick B.R. (1982) The impact of immigration on the level and distribution of economic well-being. In B.R. Chiswick, ed., The Gateway: U.S. Immigration Issues and Policies, Washington: American Enterprise Institute, pp. 289-313.

Chiswick B.R. (1986) Is the new immigration less skilled than the old? Journal of Labor Economics, 4(2), April,:68-192.

Chiswick, B.R., Y. L. Lee and P.W. Miller (2005) Longitudinal analysis of immigrant occupational mobility: A test of the immigrant assimilation hypothesis, International Migration Review, 39(2), Summer.

Chiswick, B.R. and P.W. Miller (2005) Immigrant earnings: a longitudinal analysis. Review of Income and Wealth.

Chiswick C.U., Chiswick B.R. and G. Karras (1992) The impact of immigrants on the macroeconomy, Carnegie-Rochester Conference Series on Public Policy, December, 37: 279-316.

Duleep H.O. and D.J. Dowhan (2002) Insights from longitudinal data on the earnings of US foreign born men, Demography, 39: 485-506.

Duleep H. O. and M.C. Regets (1997) Measuring immigrant wage growth using matched CPS files, Demography, 34: 239-49.

Eckstein Z. and Y. Weiss (2004) The integration of immigrants from the former USSR in the Israeli Labor Market, Journal of the European Economic Association.

Frenette M. and R. Morissette (2003) Will they ever converge? Earnings of immigrants and Canadian-born workers over the last two decades, Statistics Canada, Ottawa.

Friedberg R. (2000) You can't take it with you? Immigrant assimilation and the portability of human capital: Evidence from Israel, Journal of Labor Economics, 18(2) April: 221-251.

Hanoch G. (1961) Income differentials in Israel, Fifth Report 1959 and 1960, Jerusalem: Falk Project for Economic Research in Israel.

Horowitz J. and C.F. Manski (1998) Censoring of outcomes and regressors due to survey non-response: identification and estimation using weights and imputations, Journal of Econometrics, 84: 37-58.

$\mathrm{Hu} \mathrm{W}-\mathrm{Y}$. (2000) Immigrant earnings assimilation: estimates from longitudinal data, American Economic Review, 90: 368-72.

Hum D. and W. Simpson (2000) Closing the wage gap: economic assimilation of Canadian immigrants reconsidered, Journal of International Migration and Integration, 1: 427-41. 
Hum D. and W. Simpson (2004a) Reinterpreting the performance of immigrant wages from panel data, Empirical Economics, 29: 129-47.

Hum D. and W. Simpson (2004b) Economic integration of immigrants to Canada: a short survey, Candian Journal of Urban Research, 13: 46-61.

Juhn, Murphy and Pierce (1993) Wage inequality and the rise in returns to skill, Journal of Political Economy, 101: 314-42.

Kuznets S. (1973) Notes on the economic development of Israel, Economic Quarterly, 20: 189-209, (Hebrew).

Paltiel, Ari M. Eitan F. Sabatello and Dorith Tal (1997) "Immigrants from the former USSR in Israel in the 1990s: Demographic Characteristics and Socio-Economic Absorption. In Russian Jews on Three Continents: Migration and Resettlement Edited by Noah Lewin-Epstein, Yaacov Ro'i and Paul Ritterband, London: Frank Cass: 284-324.

Shnor Y. (1996) Assimilation in immigrant earnings. MA thesis in Economics, Hebrew University (Hebrew). 